\title{
EL CONCEPTO DE DEMOCRACIA CALIFICADA DE OTFRIED HÖFFE: UNA ALTERNATIVA FILOSÓFICA PARA HACER FRENTE A LOS PROBLEMAS PLANTEADOS POR LA GLOBALIZACIÓN
}

\author{
Joaquín Ordóñez ${ }^{1}$ \\ Mónica Natalia Martínez Mejía ${ }^{2}$
}

\section{Resumen}

La democracia cualificada es una categoría epistemológica que emerge del pensamiento de Otfried Höffe, la cual propone un modelo de sociedad responsable dentro de una comunidad jurídica internacional que pueda hacer frente a los desafíos planteados por el fenómeno de la globalización, en aras de consolidar una democracia representativa; es decir, a través de la formación de una comunidad cívica en el orden global. De ahí que necesario contribuir al estudio y desarrollo de su concepto con la finalidad de sustentar una alternativa teórica para construir el referido modelo dentro de la democracia participativa en el contexto de la hegemonía neoliberal de nuestra época.

Palabras clave: Globalización; Democracia cualificada; Ciudadanía global; Orden jurídico global.

\section{INTRODUCCIÓN}

Como humanidad nos encontramos en un tiempo de desafíos sociales, políticos y económicos que requieren ser resueltos de forma efectiva. En la llamada era global, producto de la revolución científica y tecnológica del hombre moderno, se han concebido no solo nuevas formas de relaciones humanas y económicas, sino también problemáticas que han afectado a toda la biota terráquea. Entre los problemas sociales la desigualdad, la migración, la delincuencia organizada, la violencia, el racismo y la corrupción entre otros, junto a los daños ambientales como el calentamiento global, la deforestación, la extinción de la flora y fauna, la sobreexplotación de los recursos naturales sin renovación, plantean nuevos desafíos que necesitan ser resueltos con urgencia.

Desde el Renacimiento hasta nuestros días, la razón instrumental ha cobrado el protagonismo en las ideologías de los Estados contemporáneos, como método para incrementar el potencial de la humanidad con el

\footnotetext{
${ }^{1}$ Profesor e investigador de tiempo completo de la Universidad Autónoma del Estado de México - UAEM adscrito al Centro de Investigación en Ciencias Jurídicas, Justicia Penal y Seguridad Pública. E-mail: joaquin.o@me.com

2 Estudiante del Doctorado en Estudios Jurídicos en la Universidad Autónoma del Estado de México. E-mail: nataliammejia@gmail.com
} 
objetivo de dominar la naturaleza y los hombres, se interesa únicamente en los instrumentos. Este dominio ha desplazado cualquier intento por tener una dialéctica verdadera entre hombre y naturaleza, en los últimos cuatrocientos años de la nuestra era, la razón instrumental ha derivado en un neoliberalismo exacerbado donde los intereses de la humanidad han sido desplazados por el mercantilismo y la explotación del planeta tierra.

Por lo anterior, es necesario una propuesta reflexiva a la luz del universalismo planteado por el pensador alemán Otfried Höffe, el cual nos invita a pensar en la democratización de una sociedad civil diversificada y a considerarnos no solo ciudadanos locales y domésticos pertenecientes a determinado territorio, sino como ciudadanos del mundo, individuos capaces de tener una auto-organización responsable exaltando los principios de justicia denominados derechos fundamentales, en los que se ejerciten efectivamente los derechos de ciudadanía. Es importante poner en el debate político una dialéctica entre las instituciones encargadas de salvaguardar los intereses de la sociedad -llámense poderes de Estado, organismos y tratados internacionales, entre otros- y la economía política global desde una perspectiva filosófica y a través de la teoría del derecho moderno. Se requiere analizar la globalización para contemplar la posibilidad de formar un orden jurídico global en aras de lograr una convivencia adecuada, primero dentro de las comunidades y luego entre ellas. Además, es necesario la actuación de sujetos responsables, en particular que los ciudadanos a través de una sociedad abierta promuevan: una sociedad civil fortalecida para hacer frente a los desafíos mundiales que como humanidad se tienen que resolver.

La línea que conduce este artículo se enraíza en la propuesta de las teorías del universalismo y cosmopolitismo modernos. De manera específica, la idea metodológica de Otfried Höffe sobre el modelo de democracia cualificada, misma que puede ser una alternativa teórica y epistemológica para hacer frente a los desafios de nuestro tiempo. La democracia cualificada reclama un modelo de sociedad que requiere de una acción ciudadana que se extienda más allá de las fronteras nacionales, a través de una política global organizada de una manera deliberativa como una república y democracia mundiales, por medio de la alternativa: una responsabilidad democrática global que defienda tanto los derechos humanos como los recursos naturales de nuestro planeta.

\section{CONSIDERACIONES PRELIMINARES SOBRE LA GLOBALIZACIÓN}

Se suele definir a la época actual como la era posmoderna ${ }^{3}$ en la que el tejido social se articula cada vez

\footnotetext{
${ }^{3}$ Gilles Lipovetzky afirma que lo posmoderno no es una noción clara, remite a niveles y esferas de análisis difíciles de hacer coincidir. Para tratar de ofrecer una idea a la definición de este concepto el autor se pregunta si es "¿Agotamiento de una cultura hedonista y vanguardista o surgimiento de una nueva fuerza renovadora? ¿Decadencia de una época sin tradición o revitalización del presente por una rehabilitación del pasado? ¿Continuidad renovada de la trama modernista o discontinuidad? ¿Peripecia en la historia del arte o destino global de las sociedades democráticas? El mismo pensador menciona que la sociedad occidental moderna se ha negado a circunscribir el posmodernismo a un marco regional, estético, epistemológico o cultural: si aparece una posmodernidad, esta debe designar una ola profunda y general a la escala del todo social, puesto que es cierto que vivimos unos
} 
más conforme a relaciones de consumo, individualismo e intercambios mercantiles a niveles jamás imaginados. Las relaciones económico-sociales han configurando un nuevo tipo de sociedad en el que dicho proceso de intercambios financieros parece ser una necesidad natural del individuo. Teóricos de la posmodernidad y de la globalización como Antony Guiddens (1999), Octavio Ianni (1999), Guilles Lipovetsky (2015), incluso universalistas como el propio Otfried Höffe (2007) y David Held (2007), entre otros, coinciden en establecer que el llamado proceso de globalización es un fenómeno que vivimos en un mundo de transformaciones que afectan casi a cualquier aspecto de lo que hacemos. Para bien o para mal nos vemos propulsados a un orden global que nadie comprende del todo, pero que hace que todos sintamos sus efectos (Guiddens, 1999: 56).

La globalización ha permeado en diferentes escalas y formas en la humanidad y en la naturaleza, si bien se refiere a un proceso que por antonomasia mercantiliza productos, afecta e impacta otros aspectos como en los recursos ecológicos, la cultura, las formas jurídicas, el arte, en general en la forma de vida de las sociedades capitalistas. La difusión global de las políticas económicas y de los estilos de vida basados en la industria están agotando la riqueza ecológica del planeta, colocando en peligro los recursos naturales y los servicios ambientales de los cuales depende la creciente población mundial. Pero no solo la globalización ha afectado de forma impactante la biota global, sino también el proceso de mundialización de los mercados productivos y las fuerzas laborales han originado el desplazamiento migratorio ${ }^{4}$ que desemboca en problemas raciales, culturales, lingüísticos, religiosos, es así que "emergen xenofobias, etnocentrismos, racismos, fundamentalismos, radicalismos, violencias (Ianni, 1999: 25). Como refiere Pedro De Vega (1998), en todas las latitudes proliferan nacionalismos beligerantes y aparecen extravagantes construcciones ideológicas que gravitan como elementos distorsionantes de la realidad estatal. Por ello, el nuevo orden mundial (producto de los movimientos globales) nos obliga a reflexionar sobre: las políticas del Estado en materia económica y social, el papel de las organizaciones internacionales en el contexto mundial como mecanismos de defensa y protección de los derechos humanos, el derecho internacional y el derecho interno de los estados con sus conceptos tradicionales de soberanía y ciudadanía, con la finalidad de acercarnos al impacto que tiene la globalización en la esfera de los derechos humanos entre otros.

tiempos en que las oposiciones rígidas se borran, en que se difuminan las preponderancias, en que la inteligencia del momento exige poner de manifiesto las correlaciones y homologías (Lipovetzky,2002: 80).

${ }^{4}$ Es conocido el gran problema a nivel mundial de la inmigración. En el caso específico de nuestro país tanto los inmigrantes mexicanos como centroamericanos día a día atraviesan por un sinfín de sucesos que afectan sus condiciones básicas de supervivencia, el miedo, el hambre, el frío, el calor en los territorios hostiles del desierto en la frontera entre los Estados de Sonora y Arizona, son algunos de los problemas por los que son duramente afectados, en su travesía por alcanzar el sueño americano. En Latinoamérica otro ejemplode la problemática migratoria lo hallamos en Chile, donde durante el año dos mil dieciséis más de 10 mil haitianos llegaron a este país, y en el año dos mil diecisiete ya son casi cuarenta y cuatro mil. Los desafíos que imponen dichos movimientos migratorios para los estados particulares son varios, entre ellos establecer políticas públicas migratorias globales que puedan superar las legislaciones locales para defender de manera efectiva los derechos humanos de los inmigrantes; entonces 
La globalización es unfenómeno complejo que configura un nuevo tipo de Estado y de sociedad, que junto conel desarrollo científico y los avances tecnológicos están revolucionando las distintas economías mundiales. Dicho proceso de interdependencia económica creciente del conjunto de países es provocado por el aumento del volumen y la variedad de las transacciones transfronterizas de bienes y servicios, así como de los flujosinternacionales de capitales, unida a la difusión acelerada de tecnología de carácter general (Cosulich, 2012), lo que evidencia la necesidad progresiva de que en la eraglobal se requiere organizar a los estados particulares en forma democrática siguiendo principios de justicia. Ante este escenario, la visión filosófica de Otfried Höffe sobre el proceso de globalización descrita en su obra Demokratieim Zeitalter der Globalisierung (Democracia en la época de la Globalización) 2009,cobra relevancia al formular un modelo de sociedad responsable que haga frente a los desafíos de la globalización y que enfatice la visión de una democracia participativa que busca igualdad global.En palabrasde este autor,significa ampliar la democracia de los estados particulares convirtiéndola en una democracia mundial, por medio del modelo de una sociedad responsable: una democracia cualificada que obedezca a los mismos principiospor medio de la creación de una república mundial, federal y solidaria. En esta obra Otfried Höffe describe el fenómeno de la globalización de forma renovada desde la perspectiva de la filosofía política contemporánea; analiza la globalización desde una visión filosófica poniendo en la mira las grandes cuestiones éticas vinculadas con el derecho y la política de los actuales estados. Su visión aristotélica-kantiana ha permitido que con base en autores tan esenciales revitalice la filosofía práctica de la actualidad. Sin duda su pensamiento se inscribe en un trabajo que ofrece respuestas sistemáticas a los problemas morales y políticos planteados por los movimientos globales de la época moderna.

Los problemasde Oriente medio, los grandes movimientos migratorios tanto en Europa como en América, el regreso del conservadurismo en Inglaterra y de la derecha en Estados Unidos de Norteamérica y la nueva ola de gobiernos de derecha en América Latina como en Brasil o Chile, nos obliga cuestionarelproceso deglobalización y el papel que desempeñan los estados democráticos particulares para hacerle frente. Por lo que urge proponer herramientas teóricas y metodológicasque impulsen el desarrollo de una organización democrática-jurídica que defienda efectivamente los derechos humanos en el contexto mundial complejo, pues es evidente que la política económica de los Estados compuesta de política monetaria, fiscal y social, se subordina a la valoración del sector capital globalante lo cual se ven vulnerados los derechos humanos de la comunidad internacional. Octavio Ianni (1999) refiere que el mundo entró en la era del globalismo, en donde estamos siendo desafiados por los dilemas y horizontes que se abren con la formación de la sociedad global, como una totalidad incluyente, compleja y contradictoria:

Las nociones de colonialismo, imperialismo, dependencia e interdependencia, así como las

erradicar el racismo y el nacionalismo en la cultura del país huésped es otro desafío por resolver. Por estos motivos, la perspectiva global y cosmopolita urge ser implementada en el actuar de los estados particulares (Radio Chile, 2016). 
de proyecto nacional, vía nacional, capitalismo nacional, socialismo nacional y otras, envejecen, cambian de significado, exigen nuevas formulaciones. A medida que se deshacen las hegemonías construidas durante la guerra fría declinan las potencias mundiales, envejecen o se pagan las alianzas y acumulaciones estratégicas y tácticas bajo las cuales se dibujaba el mapa político del mundo hasta 1989, cuando cayó el muro de Berlín, emblema del mundo polarizado (Ianni, 1999: 12).

El proceso de la globalización debe ocupar el lugar de mayor preocupación para los Estados democráticos contemporáneos de forma general y de manera específica para la comunidad académica y científica de cada uno de éstos. Con ello cobra relevancia la propuesta universalista de Otfried Höffe de construir un orden jurídico global a través de una república mundial, federal y subsidiaria, por medio de una sociedad responsablemisma que tenga herramientas democráticas suficientes para hacer frente al complejo fenómeno de la globalización con todas y cada una de las consecuencias que acarrea en los distintos niveles de vida de la comunidad global. Esta idearesulta visionariaal hacernos reflexionar sobre los actuales medios internacionales con los que cuenta la humanidad para hacer frente a los desafíos globales, pues ¿cómo defender los derechos humanos ante la globalización? o dicho en otros términos: ¿cuáles son los mecanismos efectivos de la humanidad para hacer frente al desafío de la globalización?

Para dar respuesta a estas interrogantes es necesario recurrir en primer lugar a una perspectiva filosófica que pueda favorecer al diálogo internacional entre las distintas comunidades y los estados particulares, pues un orden jurídico global puede ser una plataforma de intercambios directos y transversales sobre los desafíos contemporáneos que presenta la globalización con miras a favorecer la creación de conceptos centrales, prioridades y estrategias que los estados particulares tienen que adoptar para proteger los principios de justicia; es decir, derechos fundamentales. Anne Peters (2009) afirma que teóricamente las reconstrucciones académicas no dependen de las actitudes morales de los gobiernos y una buena idea no se vuelve mala simplemente porque las políticas no la acepten, se supone que el derecho, los constructos jurídicos y los argumentos jurídicos tienen un impacto en el poder.Por ejemplo, los conceptos como liberalización, transición a la democracia y democratización (O’Donnell y Schmitter, 1994) se constituyeron en Latinoamérica en un momento histórico determinante para la defensa de los derechos humanos. En el caso particular de Chile, la élite académica constituida dentro y fuera del país debatió la mejor forma de terminar la violencia, que unida a las fuerzas políticas internas organizaron la oposición contra la dictadura cívico-militar liderada por Augusto Pinochet.

Ahora bien, uno de los primeros pensadores modernos que tuvo la agudeza conceptual de proporcionar al conjunto de la filosofía la perspectiva cosmopolita fue Immanuel Kant ${ }^{5}$, el cual pensó en la idea de la

\footnotetext{
${ }^{5}$ El fundamento del cosmopolitismo moderno se halla en las ideas del gran teórico Immanuel Kant, quien en su obra Ideas para una historia universal en clave cosmopolita (1784) afirma que las acciones humanas se encuentran determinadas conforme a las leyes universales de la Naturaleza, al igual que cualquier otro acontecimiento natural. A través de la enumeración de ocho principios fundamenta su idea de república mundial, afirmando que la instauración de una sociedad civil que administre universalmente el derecho podrá hacerle frente a la fuerza de la Naturaleza. El autor supone que el problema del establecimiento de una constitución
} 
universalidad para hacer frente a los desafíos globales, así como enla reinterpretación específica actual para oponerse a las fuerzas del mercado por medio de mecanismos de acción jurídicos y morales que puedan favorecer a la sociedad global emergente. Esta perspectiva fue aún más compleja de lo que parece, pues no basta con proponer la idea de universalidad para enfrentar esa realidad económica mundial que absorbe los espacios sociales, y fortalece las desigualdades de la sociedad en general y favorece a los detentadores del poder económico que, a decir verdad, son una minoría. Para la problemática de la actualidad consideramos que la perspectiva de los universalistas actuales como Otfried Höffe (2009), David Held (2007), Antony Guiddens (1999), iniciada por Immanuel Kant (2015) es la vía epistemológica más idónea para abordar los problemas planteados por la globalización. De ahí que la construcción del concepto de democracia cualificada propuesta por el kantiano y cosmopolita Otfried Höffe puede ser una alternativa conceptual para construir el modelo de una sociedad responsable dentro de la democracia participativa en el contexto de la hegemonía neoliberal de nuestra época. Por lo anterior, es ineludible la idea de formarnos bajo una democracia cualificada, esto es, una república mundial y solidaria como respuesta filosófica a la globalización.

De Vega refiere que, queramos o no, en la época de las autopistas de la comunicación y de la globalización económica, nos vemos obligados a ser ciudadanos del mundo y reflexionar sobre el proceso de globalización haciendo que indudablemente repensemos el papel que tiene el Derecho en este proceso y sobre todo repensar el papel de los Estados particulares dentro de este escenario político-económico. Las repercusiones subyacentes de la mundialización impactan a grandes y pequeñas escalas tanto en la vida cotidiana de las personas como en la forma de vida de la sociedad en general. En esta perspectiva, se ha desplazado la razón política por la lógica de la ganancia que preside las acciones de un mercado cosmopolita. Esto es, se ha confrontado lo político con lo económico, en la que el desmoronamiento de la razón política ha propiciado que la razón económica tome la batuta de la historia:

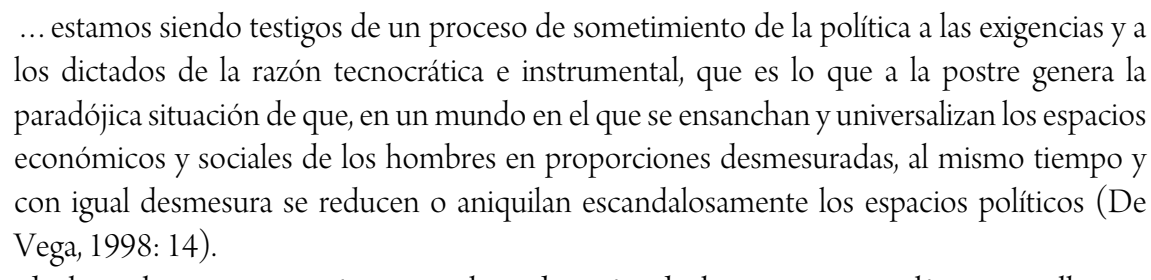

El ensanchamiento de las relaciones económicas y la reducción de los espacios políticos conlleva a cuestionar el papel actual de los Estados contemporáneos y sus políticas públicas para hacer frente a los desafíos planteados por la mundialización económica, siendo el Estado la única organización social capaz de controlar este ensanchamiento comercial que ha causado la vulnerabilidad de los derechos humanos en el plano internacional y ha propiciado una gran red de terrorismo y delincuencia organizada a lo largo del planeta.

civil perfecta depende a su vez del problema de una reglamentación de las relaciones interestatales y no puede ser resuelto sin vol.11, no. 01, Rio de Janeiro, 2018. pp. 424-444 
Puede suponerse que, junto con expansión de las empresas, corporaciones y conglomerados trasnacionales se articula con la nueva división trasnacional del trabajo y la emergencia de las ciudades globales, se verifica la declinación del estado-nación, ya que este comienza a ser obligado a compartir o aceptar decisiones y directrices provenientes de centros de poder regionales y mundiales:

Estamos viviendo un nuevo ataque de universalización del capitalismo, como método de producción y proceso civilizador. El desarrollo del modo capitalista de producción, de manera extensiva e intensiva, adquiere otro impulso apoyado en nuevas tecnologías, la creación de nuevos productos, la recreación de la división internacional del trabajo y la mundialización de los mercados. Las fuerzas productivas básicas, incluyendo el capital, la tecnología, la fuerza de trabajo y la división trasnacional del trabajo, exceden fronteras geográficas, históricas y culturales, multiplicándose las formas de articulación y contradicción. Este es un proceso simultáneo civilizador, ya que desafía, rompe, subordina, mutila, destruye, recrea otras formas sociales de vida y de trabajo, incluyendo formas de ser, pensar, actuar, sentir e imaginar (Ianni, 1999:55).

Como se refirió en párrafos anteriores, las manifestaciones concretas del proceso de aniquilación del espacio político tanto del Estado como de la sociedad civil puede ser palpable en la crisis de las sociedades capitalistas actuales a través de diversos fenómenos negativos que han sido consecuencia de la mundialización del mercado, tales como el cambio climático, la marginación, la crisis de representatividad, la violencia, la inseguridad ciudadana, el aumento de la corrupción, donde la vida del ciudadano se dirige al retiro del escenario político y social, y se reduce a una pasividad individual de consumo y ensimismamiento debido quizá al desencanto hacia el propio Estado y a la sociedad civil en general ${ }^{6}$.

En este proceso de debilitamiento social y estatal, la razón tecnológica adquiere proporciones temibles. La cuestión principal para luchar contra este ensanchamiento económico que afecta la esfera política de la ciudadanía la vendrá a ofrecer el liberalismo político: "el problema del orden social y de los principios que deben regular la vida política se subsume dentro de los requerimientos de la legitimidad racional moderna: sólo son legítimos aquellos principios que pueden ser racionalmente aceptados por todos los ciudadanos a los que han de vincular" (Rawls y Habermas, 1998: 12). Esto nos remite a la idea de acentuar la confianza o mejor dicho construir la confianza en sustentar una concepción pública de la justicia válida para las sociedades contemporáneas. Lo cual solo se puede dar a través de una reconstrucción discursiva de la noción kantiana de personalidad moral, ya que las sociedades modernas son caracterizadas por la pérdida de un referente normativo unitario capaz de vincular a todos sus miembros, aunado a la creciente autonomización de los sistemas económico y administrativo, que

solucionar previamente esto último (Kant, 2015: 41).

${ }^{6}$ El capitalismo moderno como sistema social y económico es un proceso complejo que ha cambiado la economía mundial de los últimos dos siglos de nuestra época; la crisis financiera del año 2008 es un ejemplo claro de que la política económica global ha sufrido grandes golpes y no ha podido ser capaz de solventar los requerimientos de la sociedad en sus diferentes niveles. Lejos de aquellos años donde el capitalismo había gozado de un gran triunfo sobre los demás esquemas de relaciones sociales, por ejemplo la caída del comunismo de la URSS, en la actualidad el capital sufre una crisis la cual tiene que incluir categorías de redistribución de la riqueza y de garantías sociales a nivel global para la sociedad. 
amenazan con ahogar las lógicas comunicativas del Lebenswelt (mundo de la vida). "La única forma viable de trasladar su principio de legitimidad apoyado en el principio del discurso a la sociedad como un todo es 'mediante la legalidad', a través del derecho .... La mediación institucional se convierte en el presupuesto necesario para mantener y reproducir los procesos comunicativos... (Ibídem 31).” El papel del Derecho como mecanismo organizacional de la sociedad es fundamental para que la Ética política incida de manera efectiva en los miembros de la sociedad, donde se propongan modelos cívicos y deliberativos que hagan efectivas las políticas públicas para fomentar una sociedad civil participativa e incluyente.

Dentro del debate político sostenido entre Rawls y Habermas, el último pensador propone que para luchar contra el establecimiento de la razón instrumental, pongamos en la mesa del debate: la vida buena, las condiciones de posibilidad del pluralismo, la integración normativa, la neutralidad estatal respecto a las distintas convicciones no éticas, la discusión pública de los grupos insatisfechos, y de la misma manera que los universalistas actuales, apelar a establecer una comunidad más amplia posible hacia la justicia. Lo anterior es para Höffe la pretensión de universalidad de la moral jurídica, que regula condiciones globales con validez igualmente global. No es de sobra señalar que el origen de la sociedad de consumo, característica de la comunidad global, se halla en la propia naturaleza humana:

En la base del desarrollo de la racionalidad económica, en el lado subjetivo donde radican las fuerzas motrices, hay un proceso de transformación. Desde siempre el ser humano corre un riesgo, que los griegos llamaban pleonexia, un querer siempre 'más y más y mucho más', una desmesura respecto a las necesidades e intereses. Igualmente conocemos ..., como terapia, la sophrosyne: la medida y la circunspección. Y debido al carácter universal de ambos fenómenos en la naturaleza humana, este peligro y su terapia los encontramos también en otras culturas, por ejemplo, en ... el antiguo Egipto y en la ética de la India y China. Con los comienzos de la economía racional de la Edad Moderna, en el curso de los siglos XVII y XVIII, se produce un cambio radical de mentalidad. De unas pasiones en cuanto tales son sospechosas de ilegitimidad, o también de ser vicios ilegítimos per se, nacen ahora fuerzas motrices neutras: los intereses. La vituperable 'envidia', por ejemplo, se convierte en admirada 'competencia económica', y la reprochable 'avidez' adquiere el rango de elogiable espíritu comercial. Poco después la civilización global presentará de manera prácticamente inevitable los rasgos de una sociedad de consumo (Höffe, 2007: 65).

Otro de los efectos negativos del proceso de globalización es el denominado cambio climático, consecuencia de un capitalismo exacerbado debido a diversos factores siendo el más significativo las insuficientes políticas públicas de los Estados que no han sido rigurosas para frenar la hegemonía neoliberal de los países imperialistas, “....Es un capitalismo parasítico, que va a la explotación hasta la extinción de naturaleza y recursos planetarios, incluidos bienes comunes esenciales a la existencia de la biota global, la humanidad y su civilización incluidas: océanos, forestas y atmósfera" (Saxe-Fernández 2017:17). Por ejemplo, las últimas investigaciones sobre los efectos de la globalización han concluido que las emisiones de gases de efecto invernadero (Greenhouse gas GEI por su abreviatura en inglés) son una de las principales razones del calentamiento global y el cambio climático. Entre las diversas fuentes responsables de la emisión de estos gases de efecto invernadero la generación 
de energía es la principal. El aumento de las actividades económicas facilitadas por el cada vez mayor nivel de globalización conduce a una acumulación sustancial de GEI en la atmósfera. Por lo tanto, la relación entre el crecimiento económico y la degradación ambiental sigue siendo una preocupación primordial para los encargados de formular políticas, así como para las partes interesadas (Mahbubur Rahman y Dulal Miah, 2017: $110) .^{7}$

La denominada hegemonía neoliberal favorecida por este proceso de ensanchamiento de las relaciones mercantiles ha originado el desplazamiento de la política del ámbito social y ha conducido a un planteamiento de la vida social y política de la humanidad en coordenadas distintas del funcionamiento de los Estados democráticos, estando bajo el yugo de una razón económica que crece a pasos agigantados. Bajo esta perspectiva, el desplazamiento del espacio político dentro del ámbito social ha originado que los conceptos de ciudadanía y soberanía tradicionales sean insuficientes para salvaguardar los derechos humanos en el ámbito internacional. Aún y cuando la globalización ha originado la extensión de las instituciones sociales, políticas y jurídicas a un plano internacional, ya que:

La creciente globalización va mucho más allá del ámbito de la economía y de las finanzas. Cuando en este proceso se traspasan no sólo fronteras nacionales sino también socioculturales, se plantea urgentemente la pregunta de cómo han de reaccionar los órdenes jurídicos ante las personas que traspasan esas fronteras, ante extranjeros, especialmente cuando se trata de los llamados 'exóticos', provenientes ya no de un Estado culturalmente vecino, sino de una cultura jurídica distinta. (Hoffe, 2008: 17).

Debido a la revolución tecnológica y cibernética de los últimos dos siglos de nuestra era, parece que el planeta entero se encuentra conectado gracias a los grandes sistemas de comunicación originados principalmente por el progreso de las relaciones económicas a niveles estratosféricos. Las formas mercantiles se han propagado de manera fulminante y han logrado imperar sobre los diversos niveles de vida de la humanidad. En grandes escalas participamos en las mismas formas de vida y estamos inmersos en los mismos acontecimientos alrededor del planeta, por lo que la globalización o también llamada mundialización es un fenómeno que debe ocupar un lugar central en la agenda pública de los estados democráticos contemporáneos.Ciertamente las aspiraciones de cada territorio dentro del ámbito global serán determinantes, por ejemplo, la visión europea sobre la civilización, puede ser contraria a la visión latinoamericana, lo que nos lleva a recuperar lo planteado por Peters (2009): ¿cómo

\footnotetext{
${ }^{7}$ Noam Chomsky afirmó que el cambio climático podría causar la sexta extinción, aseguró que en el 2050, por sequías, habrá 200 millones de desplazados, en su visita de noviembre de 2017 a la Ciudad de México en el simposio Los acosos a la civilización: de muro a muro, celebrado en la sala Nezahualcóyotl de la Universidad Autónoma del Estado de México. El lingüista estadounidense considerado como uno de los filósofos más influyentes de nuestra época refirió que los gobiernos de México y Estados Unidos están poniendo su grano de arena para que esto ocurra. Junto al Premio Nobel de Química, Mario Molina, quien fue uno de los primeros en advertir sobre el adelgazamiento de la capa de ozono, entre otros científicos y académicos expertos en el tema, afirmaron el riesgo del planeta frente al calentamiento global y al desafío que representa que la primera potencia del mundo Estados Unidos, esté gobernada en sus tres niveles por políticos que sostienen que el problema es un mito y que las sociedades pueden seguir utilizando sin medida los combustibles fósiles, desacatando la meta que hace dos años se planteó la Conferencia de Paris de limitar el aumento de la temperatura promedio del mundo a dos grados Celsius (Blanche, 2017).
} 
transformar o crear una comunidad jurídica internacional dentro de un orden global sin que se erosionen los intereses y tradiciones de las culturas de los países de tercer mundo ante los requerimientos de un sistema dominante? y bajo nuestra inquietud: ¿en qué medida la creación de un organismo a través del Estado será efectivo para proteger los derechos humanos en el ámbito internacional, que favorezca la cultura democrática y la ciudadanía global?, o en su caso fortalecer los mecanismos jurídicos y de ciudadanía de los actuales Estados constitucionales contemporáneos, ya que Créer un ordre juridique mondiale, c'est, avanttout, fonder la pentevers la paix et la justice globale ${ }^{8}$.

\section{EL CONCEPTO DE DEMOCRACIA CUALIFICADA DE OTFRIED HÖFFEEN LA ERA DE LA GLOBALIZACIÓN}

Para responder estos cuestionamientos expresados en el apartado anteriores necesario poner en el debate político actual una perspectiva filosóficapara entender el proceso de globalización, esto es, una reflexión que suponga la invitación a pensar en la filosofía como un recursoepistemológico y conceptual para complementar la aspiración de formar un orden de derecho y de paz globales capaz de abarcar el planeta entero a través del enriquecimiento al concepto de democracia liberal de nuestra época que:

$[\ldots]$ contribuya al desarrollo de una propuesta normativa -tanto en la ética como en la filosofía política y del derecho- que no sea etnocéntrica, sino más bien intercultural y, en ese preciso sentido, cosmopolita, capaz de elucidar las condiciones elementales del Estado de derecho y de la democracia actual para el mundo globalizado de nuestros días (Höffe, 2008: 29).

Se trata de proyectar una visión realista en torno a la pregunta: ¿cómo el legado común de la humanidad -el derecho-y además el logro político de la era moderna -la democracia liberal-pueden conservarse en la era de la globalización? (Ibídem 205).

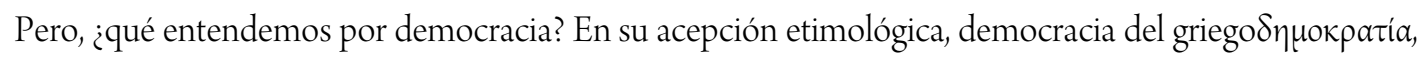
significa la forma de gobierno en la que el poder político es ejercido por los ciudadanos (RAE, 2017). La perspectiva de Robert A. Dahl (1999) ofrece una visión renovada de este concepto, pues entiende por democracia la forma de gobierno ejercida por los ciudadanos que se traduce en discusión de asuntos y la deliberación entre nosotros para alcanzar una decisión. Dice:

Una de las razones por las que constituimos esta asociación es para deliberar y discutir y decidir después sobre políticas. Pero todos estamos cualificados por igual para participar en la discusión de las cuestiones y decidir después sobre las políticas que debe seguir nuestra asociación. Por consiguiente, nuestra constitución debería apoyarse sobre tal presupuesto. Debería garantizarnos a todos nosotros el derecho a participar en las decisiones de la asociación. Por decirlo claramente, dado que todos estamos igual de cualificados,

\footnotetext{
${ }^{8}$ Traducción: "Crear un orden jurídico mundial significa, sobre todo, despertar el anhelo por la paz y la justicia globales" Otfried Höffeen El proyecto político de la modernidad, FCE. México, 2008.
} 
deberíamos gobernarnos democráticamente (Dahl, 1999:46).

Dahl entiende a esta forma de gobierno como una actividad plural y de acción de los ciudadanos que deliberan y participan en la vida política de su comunidad; además, propone la democracia participativa como aquella en la que la agenda del estado es producto de una constitución (existe la revocación del mandato y existe una rendición de cuentas para los ciudadanos). Lo cual representa una vía idónea para reconstruir el concepto de democracia liberal y participativa que en la actualidad aspiran los estados contemporáneos, además de que complementa la propuesta hoffesiana universalista de formar un orden jurídico mundial como respuesta a los diferentes desafíos de los actuales sistemas democráticos contemporáneos.

Sin embargo, la democracia participativa como agenda del Estado no es suficiente para hacer frente a los desafíos planteados por las democracias actuales y sobre todo al fenómeno de la globalización, ya que mucho de su resultado y efectividad dependen de la respuesta ciudadana por medio de la Ética y Filosofía políticas, que renueve la teoría de la ciudadanía actual y recurrir a los postulados universalistas más influyentes de nuestra época y de la política democrática contemporánea. Por ejemplo, David Held (2007) cuestiona la separación entre lo nacional y lo internacional entre la política doméstica y la extranjera tanto a nivel de las normas jurídicas como del medio ambiente; de esta forma propone una nueva arquitectura institucional que sea capaz de regular la globalización y de reducir las desigualdades. En términos del autor se trata de desarrollar instancias de gobierno en distintos niveles, del local al global, con el objetivo de imponer ciertas normas a los mercados financieros y comerciales. Aunque se opone claramente a la ideología neoliberal, David Held no predica un regreso de "todo al Estado", por el contrario, desarrolla una perspectiva en la que la economía mundializada sería regulada y sometida a imperativos sociales y ambientalistas (Johnson y Pleyers, 2008).

Tanto David Held como Otfried Höffe son coincidentes en señalar que en la actualidad, la humanidad se encuentra frente a desafíos precedentes: el cambio climático, la pobreza, las pandemias, la delincuencia organizada, el terrorismo, la migración, las amenazas de catástrofes nucleares, el racismo, el nacionalismo radical, entre otros. Ambos autores afirman que la clave para resolverlos se encuentra en la construcción de mecanismos de gobernanza global, los cuales tienen que responder a las exigencias de solidaridad, democracia, justicia social y eficacia política. Held por su parte propone un pacto global, esto es, la construcción de la ciudadanía global. Concepciones que fueron inspiradas por Immanuel Kant, y que de forma renovada se traduciría en la construcción de una ciudadanía basada en reglas y principios generales de justicia que puedan concretarse en un orden jurídico mundial.

Por lo que consideramos que la visión universalista de Held concatenada a la propuesta Höffe respecto a la creación de una república mundial, subsidiaria y federal a través de la creación de un orden jurídico mundial que demande una revolución democrática, en el que cada individuo miembro de la comunidad global ocupe un lugar primordial y ejerza un papel fundamental otorgado por una democracia participativa y deliberativa de ciudadanos 
responsables, es el complemento necesario de las instituciones políticas y debe ser el sentido cívico, como quintaesencia de distintas virtudes cívicas como su fuerza motora:

Si ... se concede la preferencia a la democracia liberal, se hará inevitable una extensión de sus elementos fundamentales hacia las relaciones globales. Al igual que una sociedad individual somete las fuerzas económicas y culturales del mercado al marco de los derechos humanos y de la democracia, las necesidades de una acción global exigen también un orden jurídico global de corte democrático, es decir, una suerte de democracia mundial liberal, que incluye una sociedad global de ciudadanos; en resumen: una República Mundial (Hoffe, 2008: 209).

Höffe afirma que por globalización se suele entender el incremento y la diversificación de las relaciones sociales a nivel mundial. Sin embargo, esta determinación le parece ser demasiado pobre y condicionada a otras cualificaciones adicionales. El autor piensa que se puede hablar de globalización como el fenómeno complejo de una comunidad de destino de la humanidad que se presenta básicamente en tres dimensiones. ${ }^{9}$. La primera, es la de una heteróclita comunidad de violencia: la comunidad de las guerras, la criminalidad organizada, los daños medioambientales, el tráfico de drogas y de seres humanos, etcétera; la segunda, la comunidad de cooperación en la que la economía desempeña un gran rol, pero no el exclusivo y, finalmente, la tercera, unacomunidad de necesidad y sufrimiento que está formada por las víctimas de la violencia producida en la primera dimensión y por las cargas y daños que tienen lugar en la segunda, como, por ejemplo, el desempleo, el hambre y los daños ecológicos (Ídem 2008).

Höffe asegura que la globalización únicamente tiene el significado de ser una tendencia y no un resultado definitivo, pues menciona que en verdad vivimos en una "civilización en tránsito", no existiendo aún una sociedad mundial unida por el cable o cableada. Siguiendo lo anterior, la visión tridimensional del autor indica una gran problemática y, por lo tanto, un gran desafío al que la humanidad tiene que responder óptimamente (Ídem, 2008), ya que la humanidad debe estar preparada para resolver las desigualdades que traen aparejadas las transacciones comerciales, y que la condición humana padece a grandes y pequeñas escalas. Pero ¿cómo responder a esta problemática?, ¿qué significa democracia cualificada en términos del autor? Höffe elabora dos modelos con gran fuerza visionaria. El primero prevé normas comunes y poderes públicos que anulan el arbitrio y la violencia privada. Se trata de un modelo que recurre al derecho y a principios de justicia privilegiando una organización democrática; al respecto señala:

Para la organización de su convivencia, la humanidad precisa sobre todo dos modelos básicos. Ambos desarrollan una fuerza visionaria: por un lado, las normas comunes y los poderes públicos reemplazan a la arbitrariedad y a la violencia privadas, y crean un ente común público de derecho. El que en lugar de la violencia hayan de reinar el derecho y la justicia, siempre y en todo lugar, y que con esa finalidad se hayan de instituir poderes

\footnotetext{
${ }^{9}$ Esta globalización tridimensional no es el único signo de la época, existen movimientos contrarios a aquella, como la regionalización y la fragmentación de grupos étnicos y culturales, la formación de corporaciones territoriales y el fortalecimiento del espíritu nacional, fenómenos que en gran parte se presentan como reacciones a la globalización, tal y como lo vivieron los catalanes independentistas en el año 2017 por ejemplo.
} 
públicos, son momentos incluso de rango jurídico moral. Me estoy refiriendo tanto al imperativo jurídico universal como al imperativo político, de índole igualmente universal. Y puesto que la legitimación del elemento central del derecho y del Estado, el poder coactivo, sólo es posible en última instancia a partir de los afectados, este doble imperativo se amplía con un tercero: con un imperativo democrático universal (Höffe, 2008: 229).

La categoría qualified democracy o democracia cualificada ${ }^{10}$, es empleada por Höffe para describir de forma hipotética a las actuales sociedades contemporáneas como entidades colectivas responsables con dos elementos característicos: auto-regulación y rendición de cuentas. En este modelo de democracia los entes colectivos se legitiman a través de individuos legales y dicha organización ocurre de manera deliberada; es decir, la sociedad se esfuerza por alcanzar principios de justicia a través del principio de responsabilidad (Höffe1999). La democracia cualificada deja espacio al libre juego de las fuerzas económicas, políticas, científicas y culturales, lo cual hace desde luego sin eliminar la competencia;aquí lo que importa es lograr la paz y erradicar el abuso mediante normas y la división de poderes.

El segundo modelo es el economicista, que da la preferencia al libre juego de fuerzas económicas según las leyes de la oferta y la demanda, sosteniendo que estas son válidas no sólo en el terreno mercantil, sino también en el de la política, la ciencia y la cultura en general (Höffe, 1999: 10).

El primer modelo es por el que se inclina Höffe, afirma que en la época de la globalización, además de organizar los estados particulares en forma democrática -siguiendolos principios jurídicos y de justicia-, es preciso ampliar la democracia particular convirtiéndola en una democracia mundial obedeciendo a los mismos principios; a fin de superar la comunidad violenta global, parece ser indispensable recurrir a un orden global jurídico y pacífico. La comunidad global de cooperación requiere de un marco imparcial de acción, exigiendo tomar medidas estatales que eviten las distorsiones de la competencia y que aseguren criterios mínimos sociales y ecológicos.Finalmente, la comunidad de necesidad y sufrimiento nos lleva a preguntar por la justicia global; por la solidaridad global y por el amor global al próximo. Al respecto el pensador afirma:

La expansión de un estado particular a una república mundial parece ser una cuestión cuantitativa y, por lo tanto, fácil: al expandir su geografía y población, la pequeña entidad política, la polis individual, se desarrolla en una cosmópolis que lo abarca todo. Esta expansión incluso promete liberar energías utópicas: ofrece soluciones a pequeña escala para los problemas de globalización que nos atemorizan y nos hacen perder nuestra existencia. Sin embargo, existe un serio desafío para seguir adelante: el escepticismo pragmático. La única manera de sofocar esas voces escépticas es resistir esa romántica "en ninguna parte", esa escurridiza promesa de salvación, y en cambio, con una conciencia realista de los problemas involucrados, desarrollar un posible "todavía no", un ideal en lugar de una utopía (ibídem Höffe 1999).

El planteamiento de Höffe respecto a la organización de una democracia mundial que obedezca a

\footnotetext{
${ }^{10}$ Qualified democracy o Democracia cualificada. Tanto la palabra qualified en inglés, cualidad en español, o qualifizierte en alemán provienen del latín qualitas, que significa cualidad, es un cultismo que se ha usado en estos idiomas como cualidad y calidad por igual. En este artículo se recurre al término democracia cualificada tal y como lo usan autores como el peruano David Sobrevilla
} 
principios jurídicos y de justicia, ordenando la competencia, trae desde luego una gran cantidad de objeciones, sin embargo, el desafío es mayor debido a la necesidad de un orden democrático mundial que enfrente los problemas planteados por la globalización, lo que en palabras de este autor origina las siguientes interrogantes: ¿los mecanismos jurídicos actuales defienden óptimamente los derechos humanos ante el fenómeno de la globalización? ¿Los conceptos de soberanía y de ciudadanía de los estados particulares dentro del marco jurídico internacional satisfacen adecuadamente las necesidades de la comunidad en el orden global? Aquellos que están convencidos de que la democracia es un ideal para la auto-organización humana deben inmediatamente subsumir la globalización -el desafío de nuestro tiempo-, bajo este mismo ideal. De inmediato demandarán la democratización global o la democracia global. Sin embargo, una filosofía sólida debe abordar el escepticismo pertinente que en el caso de la democracia, expresa dos reservas. En primer lugar, ¿este ideal consiste en una democracia pura o más bien en una democracia cualificada, que esté vinculada a los principios de la justicia, es decir, los derechos humanos? En segundo lugar, independientemente de si se elige la democracia simple o cualificada, ieste ideal depende de las presunciones de una cultura particular, la del Occidente moderno, o es válida en todas las culturas? Son las grandes interrogantes que plantea Otfried Höffe para llevar a cabo el proyecto de construcción de un modelo democrático que pueda incidir de forma efectiva en la vida cotidiana de los ciudadanos, pues apelar por la democratización de los principios de justicia, que en el contexto de Hoffe se traducen como derechos humanos, implica un cambio de paradigma, de mentalidad en la propia forma de vida de las comunidades locales; lejos de etnocentrismos y nacionalismos radicales, destacar aquello que la Ilustración le heredó a Occidente, la responsabilidad que como seres racionales tenemos ante el otro y ante la Naturaleza. Como ya se refirió la Ética y Filosofía políticas tienen la gran labor de incentivar este modelo a través de políticas públicas por medio de la construcción de instituciones globales que respalden aquello que la democracia participativa y deliberativa anhela en la interacción de los miembros sociales, el pluralismo cultural y jurídico dentro de un Estado de Derecho.

\section{LA SOCIEDAD RESPONSABLE Y LA IDEA DE LA CIUDADANÍA GLOBAL EN EL ESTADO CONTEMPORÁNEO}

El fenómeno de la globalización debe ocupar sin duda un lugar central en la agenda pública de los Estados contemporáneos; la sociedad en general se encuentra en un punto clave para reflexionar sobre el rumbo de su desarrollo,además, la modernidad exige que se reflexione sobre temas fundamentales de la ética y la filosofía política, y la relevancia de la democracia liberal y del Estado de Derecho, el cualevidencia la necesidad de repensar

(México, 2009) o las traducciones del alemán al español que ha realizado el académico mexicano Gustavo Leyva (México, 2007) respecto a las obras de Otfried Höffe. 
el tipo de gobernanza y las políticas públicas que los estado-nación están llevando a cabo para proteger los derechos de los ciudadanos de forma óptima y no solo desde la esfera doméstica sino internacional.

La ciudad global puede ser considerada un momento excepcional de la realidad social, una síntesis privilegiada del encuentro entre la geografía y la historia, una formación sociocultural en la que gran parte de la vida social aparece en forma particularmente desarrollada, acentuada, exacerbada. En la ciudad se pueden encontrar las manifestaciones más avanzadas y extremas de las posibilidades sociales, políticas, económicas y culturales del individuo y de la colectividad. Allí florecen experimentos de todo tipo, incluyendo científicos, filosóficos y artísticos, que pueden volverse patrimonio de todo el mundo (Ianni, 1999: 47).

Es notable que este rumbo agigantado de transacciones económicas obliga a repensar las formas jurídicas tradicionales que inciden en los diferentes ámbitos de la vida cotidiana de las personas, y la mundialización al ser un fenómeno que le concierne al derecho nos remite a pensar en el concepto de gobernanza global (IIJ, 2015), el cual evoca una figura emergente en la filosofía del derecho llamada constitucionalismo global, mismo puede ayudar a entender que las formas tradicionales de ciudadanía y soberanía de los sistemas estatales tienen que ser repensados y que sus ordenamientos bajo las categorías del pensamiento jurídico tradicional impide que el derecho produzca un cambio significativo en su estructura y logre incidir de forma significativa y benéfica en la protección de los derechos humanos de la sociedad global en general ${ }^{11}$.

Por su parte, Luigui Ferrajoli (1998: 173) en su texto titulado Más allá de la soberanía y la ciudadanía: un constitucionalismo global ${ }^{12}$, postula la tesis principal de que estamos ante el cambio hacia un nuevo paradigma en el derecho internacional y en la estructura de los derechos de los estados, cuyo cambio ha trastocado las viejas categorías de la visión estado-céntrica del derecho, dando lugar a profundas antinomias entre las naciones tradicionales de soberanía y ciudadanía, por un lado, y constitucionalismo y derechos humanos, por el otro. El autor menciona que los conceptos de soberanía y ciudadanía continúan informando las relaciones de cohabitación y conflicto, inclusión y exclusión, que existen entre los estados y entre los pueblos y las personas. No obstante, ambas nociones no solo han perdido mucho de su efectividad y legitimidad como medios para proporcionar paz interna e integración política y para garantizar derechos fundamentales, sino que ademásestán reñidas con lo que llama el paradigma constitucional que informa tanto la idea del Rechstaat(Estado de Derecho) como el actual entendimiento del derecho internacional (Ferrajoli, 2002; 174). La postura de Ferrajolli que

\footnotetext{
${ }^{11}$ Anne Peters considera al constitucionalismo global como una agenda política y académica que identifica y defiende la aplicación de principios constitucionalistas en la esfera internacional, en aras de mejorar la efectividad y la justicia del orden jurídico internacional. La constitucionalización global se refiere al proceso continuo, pero no lineal, de la emergencia gradual y de la creación deliberada de elementos constitucionales en el orden jurídico internacional por los actores jurídicos y políticos, respaldada por un discurso académico, en el cual se identifican y desarrollan estos elementos (Peters, 2015: 119).

${ }^{12}$ En esta obra Luigui Ferrajoli afirma que los significados tradicionales de soberanía y ciudadanía han sido puestos en cuestión por la crisis total del estado nación al que ambos están ligados: el primero, en tanto designa la completa independencia del Estado de vínculos jurídicos internos y externos; el segundo, en tanto representa el estatus subjetivo de pertenencia a una comunidad política dada. Ferrajoli desarrolla la tesis de que los cambios asociados con dicha crisis no pueden interpretarse como el advenimiento de nuevos tipos de soberanía y ciudadanía, más bien,dice, han supuesto un cambio de paradigma en el derecho internacional y en la estructura de los derechos de los estados.
} 
enfatiza las antinomias entre soberanía y la ciudadanía, viene a responder uno de los cuestionamientos planteados en líneas anteriores sobre si estos elementos -soberanía y ciudadanía- garantizan los derechos humanos. En su consideración la respuesta es negativa, ya que tienen una naturaleza excluyente y son factores de discriminación, como un "agujero negro legal" y última reliquia pre-moderna de las diferenciaciones por estatus.

El constitucionalismo global se presenta como una vía para defender los derechos humanos en el plano internacional. Anne Peters (2015) lo considera parte de una idea aún embrionaria de la constitución global. Y como coincide Ferrajoli, si bien se contempla de alguna forma en la Carta de Naciones Unidas, supone concebir la guerra, la opresión, las amenazas al ambiente y la condición del hombre y la miseria en que viven miles de personas, no como maldades naturales o incluso como simples injusticias sino como violaciones de los principios inscritos en esas Cartas como normativas vinculantes de derecho positivo. Las múltiples violaciones de derechos humanos a nivel mundial suponen como señala este autor, que ni el concepto de soberanía ni ciudadanía satisfacen los derechos humanos, pues no son mecanismos de defensa de estos a nivel global, lo que nos lleva a preguntarnos si en la actualidad existe una organización jurídica internacional que proteja a tales derechos ante el fenómeno de la globalización en sus aspectos de orden negativo. La crítica que Ferrajoli hace desde la perspectiva del constitucionalismo global enfatiza la carencia de garantías como instrumentos capaces de accionar los principios jurídicos, pues por lo visto se está en ausencia de garantías judiciales en apoyo de la paz y de los derechos humanos. Tampoco se trata de construir un gobierno local sino de construir garantías judiciales globales.

Continuando con las ideas de Ferrajoli, consideramos que el constitucionalismo global puede llegar a ser una alternativa realista para abordar los efectos negativos que enfrenta el orden mundial, como la guerra, la destrucción, el fundamentalismo islámico, los conflictos étnicos, el terrorismo, la hambruna, las redes delincuenciales que los estados particulares no pueden resolver. La construcción de una democracia cualificada se vuelve necesaria, ya que como modelo de una sociedad responsable se requiere la protección, a través de una organización jurídica internacional, esto es, un orden jurídico mundial equitativo que luche contra las hegemonías impuestas por los imperios dominantes.

Por otro lado, el concepto de ciudadanía como término local, exige ser replanteado, merece ser reestructurado bajo las ideas generales de una cultura filosófica y jurídica que tenga una visión con tendencia universalista. El problematizar en la idea de una justicia global nos remonta incluso al concepto kantiano de derecho cosmopolita (Kant,2005: 35) que pugna por el reconocimiento del ciudadano ante los Estados en un orden mundial, lo cual resultaría bastante estimulante en el plano epistemológico.

Así como la ciudadanía ha sido principalmente tutelada, regulada o administrada, también la soberanía nacional pasa a ser crecientemente tutelada, regulada o administrada. Si por un lado el estado-nación es empujado a limitar y orientar los espacios de la ciudanía, por el otro las estructuras globales de poder son empujadas a limitar y orientar los espacios de soberanía 
nacional. Además, el ejercicio de la propia ciudadanía, en los ámbitos local, nacional, regional y mundial, ha sido delimitado o agilizado por el juego entre las fuerzas preponderantes en escala global. Sucede que, aunque en proceso de formación e institucionalización, la sociedad global establece algunas de las condiciones y posibilidades de naciones y nacionalidades, así como de individuos, grupos, clases, colectividades, pueblos, movimientos sociales, partidos políticos y corrientes de opinión pública (Ianni, 1999:55).

En su obra Ciudadano económico, ciudadano del Estado, ciudadano del mundo. Ética política en la era de la globalización, Höffe (2007) imagina la idea de un sentido comunitario que va más allá del compromiso social; una lucha por el bien común, que se opone a la separación institucional entre Estado y sociedad, y contradice la tesis del creciente individualismo de la modernidad; hace hincapié en el desarrollo cívico del ciudadano y piensa que la sociedad cívica va más allá de una concepción de comunidad que se reduce a lo estatal, pues su objetivo es fomentar el bien común apelando a medios no gubernamentales, porque adquiere una responsabilidad de lo público.Afirma que se trata de construir la idea de una democracia participativa, una ciudadanización de la política, ya que la democracia se debe transformar a partir de la auto-organización libre de los ciudadanos y debe lograr una aproximación al ideal de la democracia: un poder real del pueblo.De esta forma refiere:

Las virtudes cívicas ... las condiciones personales de la democracia liberal, nada tienen que ver con las grandes preguntas existenciales. Por este motivo, no compiten con las religiones ni con las cosmovisiones, ni necesitan una legitimación comparable. Les basta con un concepto modesto: la autoorganización democrática de una convivencia lo más justa posible y abierta al sentido comunitario. ( ... )

Allí donde las virtudes cívicas florecen, las instituciones del Estado con atribuciones de coerción pueden abstenerse de ejercer la legal constricción, y la democracia se transforma en una autoorganización, y libre (en sentido enfático), de los ciudadanos. Sabiendo que una autoorganización de la sociedad sólo tiene lugar allí donde la persona misma -la ciudadaníaorganiza la sociedad, los ciudadanos armonizan las esperanzas que depositan en la comunidad con lo que ellos mismos aportan, en favor de lo cual hablan motivos que no son siquiera genuinamente morales, sino directamente pragmáticos y de prudencia (Höffe, 2007: 98).

El contenido teórico del derecho internacional constitucional aunado al desarrollo del concepto de democracia cualificada y la visión de ciudadanía de Höffe pueden proporcionar herramientas teóricas y metodológicas para dar posibles respuestas a los desafíos que enfrentan los derechos humanos dentro de la comunidad global, en aras de formar una democracia mundial dentro del emergente nuevo orden del derecho internacional. De ahí quenuestra propuesta metodológica sea contribuir a la apertura y formación de una democracia global por medio del modelo de una sociedad responsable donde se promuevan los valores fundamentales de la sociedad: pluralismo, tolerancia, honor, honradez en la política, igualdad y justicia.

Los valores de una sociedad cosmopolita pueden ayudarnos como comunidad global a combatir las desigualdades sociales (como el racismo), a enaltecer la cultura de la humanidad a través de la construcción de la ciudadaníae incidir sobre todo en el grado de participación de los individuos en los asuntos públicos. Se trata de poner el acento no ya en el Estado sino en su substrato humano, esta cuestión sugiere un derecho que no sea ya 
más la expresión del poder del Estado, en una muestra de exacerbación de la soberanía nacional, sino de una comunidad jurídica internacional de todos los pueblos (Pierré-Caps, 2000: 159). La visión contemporánea de la política y economíanos obliga a "abrir las ciencias sociales" a otro tipo de materias como la ética, filosofía política y la sociología. Estamos en el momento preciso de teorizar y elevar los niveles de discurso a consideraciones no solo pragmáticas; así como dar al Derecho el rango de arte que ha perdido ante la embestidura económica y tecnológica, de forma que no debe quedar como mera técnica instrumentaly así enfrentar el desafío de la visión posmoderna (Gómez, 2012:47).

Las ciencias sociales y humanas colaboran con la idea de que el hombre es un fin en sí mismo, elevan su protesta contra la vida des-humanizada que se aferra a la ambición exagerada de poder, a la ambición de honores y la codicia, esto es, a la caza de poder, de honor y de riqueza. Además, las ciencias humanas, mediante un contraste, hacen entendible de manera directa e indirecta el origen de la propia cultura y de la ajena; exploran formas de pensar, sentir y actuar y descubren las fuerzas motoras de la cooperación y de la competencia. Y la ética desarrolla conceptos, criterios y modelos de argumentación para la práctica personal y la práctica política (Höffe 2007,310).

Lo anterior nos anima a echar una mirada a los planteamientos filosóficos que nos preceden para incentivar el cambio hacia un modelo axiológico y ético dentro de la democracia liberal a la que pertenecemos. Existen grandes modelos teóricos y filosóficos capaces de motivar un cambio sustancial e incidir en la vida cotidiana de los ciudadanos, sin embargo, son insuficientes cuando no existe una visión pluricultural para aplicar dichos conceptos a través de políticas públicas de gobernanza tanto local como global. La teoría y práctica jurídicas deben voltear su mirada a la inclusión de las ciencias sociales y humanas en su quehacer legal para así ejercer una verdadera democracia que compita efectivamente con los requerimientos de las sociedades contemporáneas.

\section{CONCLUSIÓN}

Nos encontramos en un punto clave del desarrollo de la civilización contemporánea y la globalización para bien o para mal ha cambiado la forma de vida de la sociedad en general. Para las políticas de los estados particulares, los conceptos de soberanía y ciudadanía resultan ser insuficientes para defender los principios de justicia; es decir, los derechos humanos en el plano internacional. La idea de la universalización kantiana es una categoría que puede proporcionar elementos para construir lo que Otfried Höffe denomina como "democracia cualificada", la cual es aún un concepto emergente en su pensamiento, un modelo de sociedad responsable que pese a considerarlo él mismo como un ideal, afirma que puede ser realizable. La idea de universalización hace pensarnos no como miembros locales y domésticos sujetos a los estatutos de un estado en particular, sino como ciudadanos cosmopolitas, ciudadanos del mundo.

La democracia cualificada es un modelo de sociedad responsable que es posible construir bajo la visión 
de una república mundial, la cual es una respuesta filosófica a la globalización, bajo la perspectiva de Otfried Höffe. El Estado contemporáneo se enfrenta a diversos desafíos, pues la mundialización lo ha desplazado a él y al Derecho. Por el contrario, la mercantilización ha tomado la dirección del rumbo de la humanidad, por lo que es imprescindible que la idea de una sociedad democrática global y participativa se instaure en la vida de los ciudadanos dentro del nuevo orden mundial. De ahí que la construcción de una democracia cualificada puedaser una alternativa conceptual para la formación de una sociedad responsable dentro de la democracia participativa en el contexto de la hegemonía neoliberal de nuestra época.

\title{
THE CONCEPT OF QUALIFIED DEMOCRACY OF OTFRIED HÖFFE: A PHILOSOPHICAL ALTERNATIVE TO DEAL WITH THE PROBLEMS POSED BY GLOBALIZATION
}

\begin{abstract}
Qualified democracy is an epistemological category that emerges from the thought of Otfried Höffe, which proposes a model of responsible society within an international legal community that can face the challenges posed by the phenomenon of globalization, in order to consolidate a democracy representative that is, through the formation of a civic community in the global order. Hence, it is necessary to contribute to the study and development of its concept in order to sustain a theoretical alternative to build the aforementioned model within participatory democracy in the context of the neoliberal hegemony of our time.
\end{abstract}

Keywords: Globalization; Qualified democracy; Global citizenship; Global legal order

\section{FUENTES DE INFORMACIÓN}

ACNUR, 2017. La agencia de la ONU para refugiados, http://www.acnur.org/el-acnur/ Consulta 18 de mayo del 2017.

COSULICH AYALA, Jorge. http://www.ciat.org/index.php/es/blog/item/60-consecuencias-tributarias-de-laglobalizacion.html?tmpl=component\&print=1. Consulta 24 de junio del 2017.

DAHL, Robert. La democracia. Una guía para los ciudadanos. Taurus. Argentina 1998.

DE VEGA GARCÍA, "Mundialización y derecho constitucional: La crisis del principio democrático en el constitucionalismo actual”, Revista de Estudios Políticos (Nueva Época) Núm. 100, Abril-Junio 1998, España, 1998.

DIARIO U CHILE, Año IX, Sección Nacional. http://radio.uchile.cl/2016/09/25/la-dura-realidad-de-losmigrantes-haitianos-en-chile/ Consulta 10 de noviembre del 2017. 
FERRAJOLI, Luigui, "Más allá de la soberanía y la ciudadanía: un constitucionalismo global” en Isonomía: Revista de teoría y filosofía del derecho, N‥9, pp. 173- 184. México, DF. Instituto Tecnológico Autónomo de México, 1998.

GÓMEZ GALLARDO, Perla. Filosofía del derecho. Iure. México, 2012.

GUIDDENS, Antony. Un mundo desbocado. México. Taurus. 1999.

HABERMAS, Jürguen y Rawls, Jonh. Debate sobre el liberalismo político. Barcelona. Paidós, 1998.

HELD, David. Modelos de democracia. Alianza editorial, España, 2007.

HÖFFE, Otfried. Ciudadano económico, ciudadano del Estado, ciudadano del mundo. Ética política en la era de la globalización. Katz, Argentina, 2007.

Democracy in an age of Globalization, Spinger, USA. 2009

Derecho intercultural. España. Gedisa. 2007

Estudios sobre el ideal cosmopolita. Barcelona. Cátedra. 2017.

El proyecto político de la modernidad. México. Fondo de Cultura Económica. México, 2008.

INSTITUTO DE INVESTIGACIONES JURÍDICAS (2015), Gobernanza Global y Cambio Estructural del Sistema Jurídico Mexicano, en línea, disponible en: http:/ /historico.juridicas.unam.mx/gobernanza/.

JOHNSON, Alan y Pleyers, Geoffrey. Globalización, democracia y mercados: una alternative socialdemócrata. Entrevistas con David Held. Revista Sociológica, año 23, número 66, pp. 187-224, enero-abril 2008.

KANT, Immanuel, Ensayos sobre la paz, el progreso y el ideal cosmopolita. Cátedra. Madrid. 2010.

IANNI, Octavio, La era del globalismo. México. Siglo XXI. México. 1999.

LIPOVETSKY, Guilles. La era del vacío. Barcelona. Anagrama. 2015.

MAHBUBUR RAHMAN, Syed y DulalMiah, Mohammad, 2017 "The impact of sources of energy production on globalization: Evidence from panel data analysis" en Renewable and Sustainable Energy Reviews. Volumen 74, July 2017, pp. 110-115.

NATERAS GONZÁLEZ, Martha Elisa, 2012 "Ciudadano económico, ciudadano del Estado, ciudadano del mundo. Ética política en la era de la globalización de Otfried Höffe” en Espacios Públicos, vol. 15, № 35, septiembre-diciembre, 2012, pp. 197-202. Universidad Autónoma del Estado de México.

O'DONNELL, Guillermo y Schmitter, Philippe, Conclusiones tentativas de las democracias inciertas, vol. 4. Paidós. Barcelona. 1994

PETERS, Anne, "Los méritos del constitucionalismo global" en Fabra Zamora, Jorge Luis y García Jaramillo, Leonardo (Coords), Filosofia del Derecho Constitucional. Cuestiones fundamentales. México. Universidad Nacional Autónoma de México. Instituto de Investigaciones Jurídicas. 2009 
PETRICH, Blanche. El cambio climático podría causar la sexta extinción, dice el lingüista. Periódico La Jornada, Sección Política. Ciudad de México. Año 33. Número 11963. http://www.jornada.unam.mx/2017/11/16/politica/009n1 pol. Consulta 16 de noviembre del 2017.

PIERRÉ-CAPS, Stéphane "Las constituciones demóticas o las mutaciones de la constitución en el umbral del siglo XXI" en Revista Teoría y Realidad Constitucional, núm. 5, 1r semestre 2000, pp. 143-160. España. Universidad Nacional de Educación a Distancia, 2000.

SAXE-FERNÁNDEZ, John. "EU: oligarquía vs mundo". Periódico La Jornada, Sección Economía. Ciudad de México. Año 33. Número 11789. http://www.jornada.unam.mx/2017/05/25/economia/023aleco?partner=rss Consulta 25 de mayo del 2017.

SOBREVILLA, David. La filosofía del derecho alemán actual de orientación racionalista: Estudios sobre R Alexy, K Günther,J.Habermas y O. Höffe, México, Fontamara, 2008.

REAL ACADEMIA DE LA LENGUA ESPAÑOLA (RAE). http:/ / www.rae.es/ consulta 21 de mayo de 2017.

Trabalho enviado em 12 de dezembro de 2017.

Aceito em 01 de janeiro de 2018. 